Hydrol. Earth Syst. Sci., 17, 2375-2391, 2013

www.hydrol-earth-syst-sci.net/17/2375/2013/

doi:10.5194/hess-17-2375-2013

(C) Author(s) 2013. CC Attribution 3.0 License.

\title{
A global water scarcity assessment under Shared Socio-economic Pathways - Part 1: Water use
}

\author{
N. Hanasaki ${ }^{1}$, S. Fujimori ${ }^{1}$, T. Yamamoto ${ }^{2}$, S. Yoshikawa ${ }^{3}$, Y. Masaki ${ }^{1}$, Y. Hijioka ${ }^{1}$, M. Kainuma ${ }^{1}$, Y. Kanamori ${ }^{1}$, \\ T. Masui ${ }^{1}$, K. Takahashi ${ }^{1}$, and S. Kanae ${ }^{3}$ \\ ${ }^{1}$ National Institute for Environmental Studies, Tsukuba, Japan \\ ${ }^{2}$ Nagaoka National College of Technology, Nagaoka, Japan \\ ${ }^{3}$ Tokyo Institute of Technology, Tokyo, Japan
}

Correspondence to: N. Hanasaki (hanasaki@ nies.go.jp)

Received: 28 November 2012 - Published in Hydrol. Earth Syst. Sci. Discuss.: 18 December 2012

Revised: 19 May 2013 - Accepted: 22 May 2013 - Published: 1 July 2013

\begin{abstract}
A novel global water scarcity assessment for the 21 st century is presented in a two-part paper. In this first paper, water use scenarios are presented for the latest global hydrological models. The scenarios are compatible with the socio-economic scenarios of the Shared Socio-economic Pathways (SSPs), which are a part of the latest set of scenarios on global change developed by the integrated assessment, the IAV (climate change impact, adaptation, and vulnerability assessment), and the climate modeling community. The SSPs depict five global situations based on substantially different socio-economic conditions during the $21 \mathrm{st}$ century. Water use scenarios were developed to reflect not only quantitative socio-economic factors, such as population and electricity production, but also key qualitative concepts such as the degree of technological change and overall environmental consciousness. Each scenario consists of five factors: irrigated area, crop intensity, irrigation efficiency, and withdrawal-based potential industrial and municipal water demands. The first three factors are used to estimate the potential irrigation water demand. All factors were developed using simple models based on a literature review and analysis of historical records. The factors are grid-based at a spatial resolution of $0.5^{\circ} \times 0.5^{\circ}$ and cover the whole 21 st century in five-year intervals. Each factor shows wide variation among the different global situations depicted: the irrigated area in 2085 varies between $2.7 \times 10^{6}$ and $4.5 \times 10^{6} \mathrm{~km}^{2}$, withdrawal-based potential industrial water demand between 246 and $1714 \mathrm{~km}^{3} \mathrm{yr}^{-1}$, and municipal water between 573 and $1280 \mathrm{~km}^{3} \mathrm{yr}^{-1}$. The water use scenarios can be used
\end{abstract}

for global water scarcity assessments that identify the regions vulnerable to water scarcity and analyze the timing and magnitude of scarcity conditions.

\section{Introduction}

All societal and economic activities depend on water. The rapid and continuous growth of population and economic activity, mainly in developing countries, is increasing water use globally. Water availability is also changing because of human-induced climate change (Vörösmarty et al., 2000; Oki and Kanae, 2006; Kundzewicz et al., 2007). A number of studies have assessed the impact of global changes (i.e. socio-economic and climatic change) on water use and availability (Vörösmarty et al., 2000; Alcamo et al., 2003a, b, 2007; Arnell, 2004; Oki and Kanae, 2006). These studies have identified water-scarce regions in baseline periods by compiling statistical data for water use and availability and have projected future scarcity using numerical models. Hereafter we refer to such reports as global water scarcity assessments.

Although very successful, the earlier water scarcity assessments need to be updated and refined for three reasons. First, most were based on a conventional set of global change scenarios for the 21 st century presented in the socioeconomic scenarios of the Special Report on Emission Scenarios (SRES; Nakicenovic and Swart, 2000) and the climate scenarios of the Coupled Model Intercomparison Project Phase 3 (CMIP3; Meehl et al., 2007). A new set of global 
change scenarios has been released (Moss et al., 2010), consisting of the radiative forcing (i.e. greenhouse gas (GHG) emission) scenario of the Representative Concentration Pathways (RCPs; van Vuuren et al., 2011), the climate scenarios of the Coupled Model Intercomparison Project Phase 5 (CMIP5; Taylor et al., 2012), and the socio-economic scenarios of the Shared Socio-economic Pathways (SSPs; Kriegler et al., 2012; O'Neill et al., 2012). The RCPs and SSPs were independently developed. To make use of the latest achievements of the integrated assessment, the IAV (climate change impact, adaptation, and vulnerability assessment) and climate modeling community, global water scarcity assessments should utilize the new set of scenarios. Second, in most earlier water scarcity assessments, water use scenarios were associated with quantitative socio-economic scenarios, but only weakly with qualitative scenarios in many cases. The SSPs depict five substantially different future world situations (see Sect. 2 for details), and water use scenarios are therefore required to reflect the key qualitative concepts underpinning each SSP. Third, most of the earlier studies assessed water availability and use over an annual time resolution. This resolution may overlook seasonal and interannual water scarcities caused by variations in water availability and use (Hanasaki et al., 2008b). This is particularly important in climate change impact assessment when analyzing whether increases in precipitation and runoff will alleviate water scarcity.

Here we present a novel global water scarcity assessment using a global hydrological model called H08 (Hanasaki et al., 2008a, b). H08 simulates the natural water cycle (related to water availability) and major human activities (related to water use), such as the water abstraction and reservoir operation. It calculates the water availability and use in daily time intervals, which enables the assessment of water scarcity in sub-annual time intervals. We ran H08 using the new set of scenarios (i.e. RCPs, CMIP5, and SSPs).

We faced two key challenges. First, because the SSPs include neither quantitative nor qualitative scenarios for water use, we had to develop them from scratch. Second, because there are no clear guidelines or relevant earlier studies on the new set of scenarios, we had to establish an effective way to use them.

The study is presented in two papers. This first paper describes water use scenarios that are compatible with the SSPs. The scenario consists of five factors: the irrigated area, the crop intensity, the irrigation efficiency, and the withdrawal-based potential industrial and municipal water demands. The first three factors are required to estimate the potential irrigation water demand with H08. The second paper (Hanasaki et al., 2013) describes the setup and results of water scarcity assessments, taking into account sub-annual water scarcity. The structure of the first paper is as follows. In Sect. 2, the latest socio-economic scenarios (SSPs) are introduced. In Sect. 3, water use scenarios in earlier reports are extensively reviewed. In Sect. 4, based on a literature review, new models for irrigation, industrial, and municipal water use are developed. An intermediate water use scenario is then developed, which is independent of the SSPs. Section 5 reports how water use scenarios compatible with the SSPs were developed by linking the intermediate water use scenario and the SSPs. In Sect. 6, the water use scenarios are discussed and compared with earlier studies. In Sect. 7, we conclude the former part of the study. A water scarcity assessment using the water use scenarios is reported in the accompanying paper (Hanasaki et al., 2013).

We define the technical terms used to discuss water availability and use as follows. Water availability refers to available water resources, constrained by the physical hydrological cycle and human activities (e.g. water abstraction and regulation) in river basins. Water use is a general term for the utilization of water. Water consumption is water evaporated during use. Water withdrawal indicates the removal of water from a source, including water consumption, return flows, and evaporation loss during delivery. Potential water demand is the estimated water use accompanying human activities regardless of water availability.

\section{Shared Socio-economic pathways}

The SSPs are new socio-economic scenarios for use in global climate change studies (Kriegler et al., 2012; O'Neill et al., 2012). The SSPs depict five different global situations (SSP1-5) with substantially different socio-economic conditions. Each SSP contains a quantitative scenario and a narrative (qualitative) scenario.

The narrative scenarios have been well documented by O'Neill et al. (2012), and thus only a brief summary is presented here. The five SSPs can be placed in a conceptual space of two dimensions (see Fig. 1a) where the horizontal axis represents socio-economic challenges for adaptation. SSPs with higher values indicate socio-economic conditions that would make it more difficult to adapt to a changing climate. The vertical axis represents socio-economic challenges for mitigation. SSPs with higher values indicate socioeconomic conditions that would make it more difficult to reduce GHG emissions.

SSP1 (Sustainability) represents a sustainable world where it is easy to mitigate and adapt to climate change because of the rapid development of low-income countries, reduced inequality, rapid technology development, and a high level of awareness regarding environmental degradation. Good yieldenhancing technologies for agricultural land are also incorporated. SSP2 (Middle of the Road) represents conditions where the socio-economic trends of recent decades continue. Reductions in resource use and energy intensity are achieved at historic rates. SSP3 (Fragmentation) represents conditions where it is difficult to mitigate and adapt to climate change because of extreme poverty and a rapidly growing population. There is serious degradation of the environment, and 
(a)

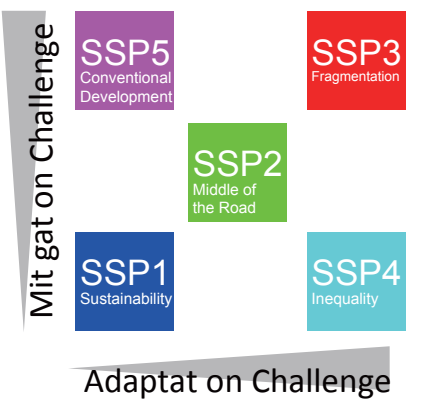

(b)

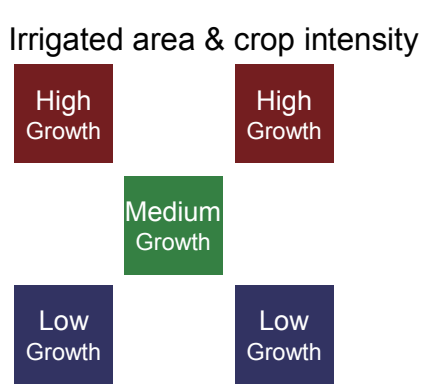

(c)

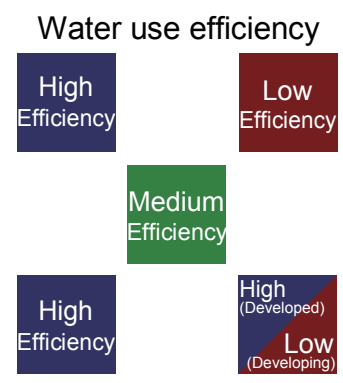

Fig. 1. (a) The five SSPs in a conceptual space of adaptation and mitigation challenges (after O'Neill et al., 2012). (b) Scenarios for irrigated area and crop intensity. (c) Scenarios for water use efficiency.

technological change in the energy sector is slow. Because of the limited coordination between regions, use of local energy resources is enhanced. SSP4 (Inequality) represents a highly unequal world both within and across countries. Crop yields would be high in industrial farming, but low for smallscale farming. SSP5 (Conventional Development) represents a situation where it is easy to adapt owing to robust economic growth, but difficult to mitigate the effects of climate change because the energy system is dominated by fossil fuels. Agro-ecosystems are highly managed, building on strong technological progress in the agricultural sector. Land use management is generally very resource intensive including the management of water systems. Table 1 summarizes the key details of each SSP as they relate to water use.

The quantitative scenarios of the SSPs cover the whole 21 st century, including population, gross domestic product (GDP), and other relevant factors; however, the final products are currently (as of October 2012) under review. In this study, the provisional quantitative SSPs developed by the Asia-Pacific Integrated Model (AIM; Kainuma et al., 2002) of the National Institute for Environmental Studies, Japan, were used (hereafter AIM-SSPs). The quantitative scenarios of the AIM-SSPs could vary from those that are finally settled, but it is unlikely that they will be totally different. The AIM-SSPs include eight socio-economic variables: GDP, population, primary energy, GHG emissions, electric production, and the value added for primary, secondary, and tertiary industries. The world is subdivided into 12 regions (Oceania, Japan, China, India, Rest of Asia, North America, Latin America, EU, Rest of Europe including Baltic countries, Former Soviet Union excluding Baltic countries, Middle East, and Africa). It covers the period from 2005 to 2100 at $5 \mathrm{yr}$ intervals. Figure 2 shows population, GDP, and electricity production for each SSP.

The SSPs do not include any climate policy and all adopt the business as usual (BAU) scenario in terms of GHG emission (Kriegler et al., 2012). The emission paths used in SSP1-5 roughly correspond to RCP6.0, RCP8.5 (strictly speaking, in between RCP6.0 and RCP8.5), RCP8.5,
RCP6.0, and RCP8.5, respectively. Scenarios relating to climate policy for the SSPs, called the Shared Climate Policy Assumptions (SPA; Kriegler et al., 2012), have been proposed but remain under discussion. In this study, we assumed SSP1-5 would correspond to RCP2.6, RCP4.5, RCP6.0, RCP2.6, and RCP6.0, respectively, when climate policy was included. These settings are based on a straightforward interpretation of the mitigation challenge of SSPs (the vertical axis of Fig. 1a). Because the SSP1 and SSP4 are less challenging to mitigate, we selected RCP2.6 for them. In contrast, the SSP3 and SSP5 are indicated as more challenging, so we selected RCP6.0 for them. This is a tentative assumption and may need to be revised once the theoretical background underpinning the SPA has been fully reviewed. The scenario matrix for the SSPs and RCPs is shown in Fig. 3.

As mentioned above, the SSPs do not include a water use scenario, but because each SSP depicts substantially different global situations, we can infer that irrigation, industrial, and municipal water use must vary among the scenarios. Although far from sufficient, the different narrative scenarios provide clues allowing for speculation regarding water use. On the basis of these clues, we developed the water use scenarios presented in this study.

\section{Literature review and modeling strategy}

The development of a global water use scenario (i.e. projection of future potential water demand) has been attempted for decades (earlier efforts published from 1967 to 1997 are summarized in Fig. 11.1 of Shiklomanov and Rodda, 2003). Here we review the existing literature regarding water use scenarios, which have been developed mainly for global hydrological models, and show the modeling strategy of this study. This section also introduces key technical terms and concepts for water use modeling. 
Table 1. Summary of the narrative scenarios of the SSPs.

\begin{tabular}{llllll}
\hline & SSP1 & SSP2 & SSP3 & SSP4 & SSP5 \\
\hline Technology development & High & Medium & Low & High in developed countries but low in others & High* \\
Environmental consciousness & High & Medium & Low & - & Low $* *$ \\
Crop yields & - & - & - & High in industrial farming, but low for small-scale farming & - \\
\hline
\end{tabular}

* O'Neill et al. (2012) noted that "Land use management is generally very resource intensive including the management of water systems". Although it is a contradiction, we assumed that the high technology development of SSP5 leads to water savings similar to SSP1. ** O'Neill et al. (2012) described a "highly engineered environment, highly managed land use and water intensive world".
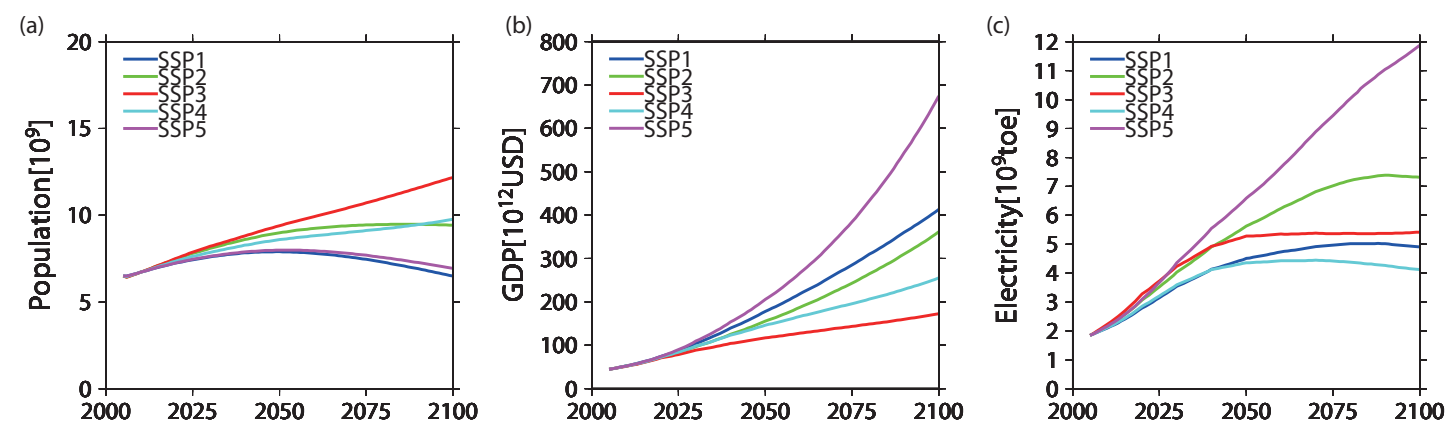

Fig. 2. Socio-economic factors of AIM-SSP. (a) Population, (b) GDP, and (c) electricity production of each SSP.

\begin{tabular}{|c|c|c|c|c|}
\hline & RCP2.6 & \multirow[t]{2}{*}{ RCP4.5 } & RCP6.0 & \multirow[t]{2}{*}{ RCP8.5 } \\
\hline SSP1 & SSP1 policy & & SSP1 BAU & \\
\hline SSP2 & & SSP2 policy & & SSP2 BAU \\
\hline SSP3 & & & SSP3 policy & SSP3 BAU \\
\hline SSP4 & SSP4 policy & & SSP4 BAU & \\
\hline SSP5 & & & SSP5 policy & SSP5 BAU \\
\hline
\end{tabular}

Fig. 3. Scenario matrix of SSPs and RCPs.

\subsection{Irrigation water withdrawal}

Agricultural water withdrawal accounts for $70 \%$ of total global water withdrawal (FAO, 2011). Because irrigation accounts for most agricultural water withdrawal (Shiklomanov, 2000), we omitted other uses such as livestock drinking water.

In earlier reports, future potential irrigation water demand scenarios were developed using statistical models on a national or regional scale (e.g. Seckler et al., 1998; Shiklomanov, 2000; Oki et al., 2003). These models were simple regression models, with historical trends of national or regional irrigation water withdrawal being explained by basic socio-economic variables such as population and GDP.

Recently, global hydrological models (e.g. Alcamo et al., 2003a; Hanasaki et al., 2008a; Rost et al., 2008; Wisser et al., 2010; Wada et al., 2011) and macro-scale crop growth mod- els (Liu et al., 2009; Liu and Yang, 2010) have been used to develop potential irrigation water demand scenarios. These models estimate potential irrigation water demand biophysically and have been heavily influenced by the work of Döll and Siebert (2002).

Here we review the methodology of Döll and Siebert (2002) in detail because it also plays a key role in this study. They first developed a digital map of the global irrigated area $A_{\text {irg }}$ at a spatial resolution of $0.5^{\circ} \times 0.5^{\circ}$ longitude and latitude (Döll and Siebert, 2000), and this map has been continuously updated (Siebert et al., 2005, 2006). They then established a methodology to estimate global crop water requirements by applying the CROPWAT model (Smith, 1992). CROPWAT is a numerical model that calculates potential irrigation water demand in the following way. (1) The crop-specific potential evapotranspiration $E_{\text {pot }}$ is estimated during the cropping period. (2) The effective precipitation $P_{\text {eff }}$ is estimated, taking into account meteorological conditions. (3) The crop water requirements are estimated by calculating the difference between crop-specific potential evapotranspiration and effective precipitation. (4) The consumption-based potential irrigation water demand is estimated by multiplying by the irrigated harvested area $A_{\mathrm{hvs}}$. (5) The withdrawal-based potential irrigation water demand is estimated by dividing by a factor called the irrigation efficiency $e_{\text {irg }}$. Multiple cropping is also taken into account. In this case, the total irrigated harvested area may exceed $A_{\mathrm{irg}}$. The ratio of $A_{\mathrm{hvs}}$ to $A_{\text {irg }}$ is called the crop intensity $\left(i_{\text {irg }}\right)$.

The above review indicates that five factors are required to estimate potential irrigation water demand: $E_{\text {pot }}, P_{\text {eff }}, A_{\text {irg }}$, 
Table 2. Projection of irrigated area, crop intensity, and irrigation efficiency in earlier reports.

\begin{tabular}{|c|c|c|c|c|c|c|c|}
\hline Reference & Scenario & Population & GDP & $\begin{array}{l}\text { Irrigated area reported } \\
\text { in the literature }\left(10^{6} \mathrm{ha}\right)\end{array}$ & $\begin{array}{l}\text { Irrigation- } \\
\text { equipped } \\
\text { area }\left(\% \mathrm{yr}^{-1}\right)\end{array}$ & $\begin{array}{r}\text { Crop } \\
\text { intensity } \\
\left(\% \mathrm{yr}^{-1}\right)\end{array}$ & $\begin{array}{r}\text { Irrigation } \\
\text { efficiency } \\
\left(\% \mathrm{yr}^{-1}\right)\end{array}$ \\
\hline Rosegrant et al. (2002) & & UN 1998 med & original & $375(1995)^{* *}, 441(2025)^{* *}$ & - & & - \\
\hline Bruinsma (2003) & & UN 2001 med & WB 2001 & $202(2000)^{* * *}, 242(2030)^{* * * *}$ & 0.6 & 0.4 & 0.3 \\
\hline Alcamo et al. (2005) & MA-TG & MA-TG & MA-TG & $239(2000)^{* * *}, 252(2050)^{* * *}$ & 0.11 & & $0.15-1.2$ \\
\hline de Fraiture et al. (2007) & CA-Irrigated area expansion & MA-TG & MA-TG & $340(2000)^{*}, 450(2050)^{*}$ & 0.6 & & - \\
\hline de Fraiture et al. (2007) & CA-Comprehensive & MA-TG & MA-TG & $340(2000) *, 394(2050) *$ & 0.3 & & - \\
\hline de Fraiture et al. (2007) & CA-Irrigated yield improve & MA-TG & MA-TG & $340(2000)^{*}, 370(2050)^{*}$ & 0.15 & & - \\
\hline de Fraiture et al. (2007) & CA-Rainfed area expansion & MA-TG & MA-TG & $340(2000)^{*}, 340(2050)^{*}$ & 0 & & - \\
\hline de Fraiture et al. (2007) & CA-Rainfed yield improve & MA-TG & MA-TG & $340(2000)^{*}, 340(2050)^{*}$ & 0 & & - \\
\hline de Fraiture et al. (2007) & CA-Trade & MA-TG & MA-TG & $340(2000)^{*}, 340(2050)^{*}$ & 0 & & - \\
\hline Rosegrant et al. (2009) & & UN 2005 med & MA-TG & $433(2000)^{* *}, 473(2050)^{* *}$ & 0.06 & 0.15 & 0 \\
\hline
\end{tabular}

* Harvested area, ** potential irrigated area, *** area equipped irrigation. MA: Millennium Ecosystem Assessment, CA: Comprehensive Assessment, UN: United Nation population prospects, WB: World Bank, TG: Techno Garden, med for medium variant projection.

Table 3. Summary of industrial water withdrawal estimation models in earlier studies.

\begin{tabular}{|c|c|c|c|}
\hline References & Drivers & Technological change & Structural change \\
\hline Alcamo et al. (2003a, 2007) & Electricity production & Parameter & Per capita GDP \\
\hline Shen et al. (2008) & Electricity production & & Primary energy, GDP \\
\hline $\begin{array}{l}\text { Voß and Flörke (2010), Flörke et al. (2013) } \\
\text { manufacturing water }\end{array}$ & $\begin{array}{l}\text { Manufacturing output expressed in } \\
\text { gross value added }\end{array}$ & Parameter & GDP \\
\hline $\begin{array}{l}\text { Voß and Flörke (2010), Flörke et al. (2013) } \\
\text { thermal power cooling water }\end{array}$ & Thermal electricity production & Parameter & Fraction of cooling type \\
\hline Hayashi et al. (2012) & $\begin{array}{l}\text { Sector-wise production of } \\
\text { manufacturing sectors }\end{array}$ & & \\
\hline
\end{tabular}

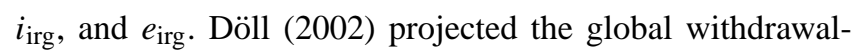
based potential irrigation water demand for the 2020s and 2070s under different climate scenarios using two global climate models and one GHG emission scenario, in order to account for changes in $E_{\text {pot }}$ and $P_{\text {eff. However, }} A_{\text {irg }}, i_{\text {irg }}$, and $e_{\text {irg }}$ were fixed in that study. Alcamo et al. (2007) assessed water scarcity using the WaterGAP 2 model under multiple scenarios. They set a single scenario of $e_{\text {irg }}$ for both the SRES A2 and B2 scenarios, but $A_{\text {irg }}$ and $i_{\text {irg }}$ were fixed because the SRES did not include these factors and there were diverse views regarding future trends. Because $A_{\text {irg }}, i_{\text {irg }}$, and $e_{\text {irg }}$ directly influence the future potential irrigation water demand, it is a challenge to establish scenarios based on these three terms.

We identified five comprehensive reports regarding agriculture and food, which included a quantitative projection of irrigation: Rosegrant et al. (2002), Bruinsma (2003), Alcamo et al. (2005), de Fraiture et al. (2007), and Rosegrant et al. (2009). Details regarding the socio-economic scenarios used in these studies are highly variable, but all of them used the population scenario of the UN medium variant projection. Note that Alcamo et al. (2005) and de Fraiture et al. (2007) used the population scenario of the Techno Garden scenario of the Millennium Ecosystem Assessment (Alcamo et al., 2005), which is similar to the UN medium variant projection. In addition, Alcamo et al. (2005) proposed four irrigation scenarios in their study (Global Orchestration, Order from Strength, Adapting Mosaic, and Techno Garden), but we only referred to the Techno Garden irrigation scenario because its population scenario is similar to those of the other four reports.

Table 2 presents a summary of these five studies. Although the population scenarios are not very different, the projections of the global irrigated area vary widely. Among the five studies, the irrigated area growth rate used by Rosegrant et al. (2009) was the smallest, and that of Bruinsma (2003) was the largest. All of the studies predicted the states of the food supply and agriculture for specific years (2025, 2030, and 2050); transient states were not described. Although climate change scenarios cover the whole 21 st century, none of the studies have described the world beyond 2050 except Alcamo et al. (2005). Furthermore, except for Bruinsma (2003) and Rosegrant et al. (2009), the studies did not separate the growth of the irrigated area and crop intensity.

It was initially confusing why these studies have such a wide range of irrigation projections. All the studies present scenarios for the growth of crop yield and cropland to meet food demand. However, there is a limited explanation of how the growth in crop yields would be achieved and how much crop production would result from irrigated agriculture. To answer these questions, region-specific information is required regarding the future trends of irrigation, fertilizer and pesticide applications, improvements in agricultural technology, and other related factors. However, these details are not 
Table 4. Summary of municipal water withdrawal estimation models in earlier studies.

\begin{tabular}{llll}
\hline References & Drivers & Technological change & Structural Change \\
\hline Alcamo et al. (2003a, 2007) & Population & Parameter & \\
Shen et al. (2008) & Population, GDP & \\
Voß et al. (2009), Flörke et al. (2013) & Population, GDP per capita & Parameter & Parameter \\
Hayashi et al. (2012) & Population, GDP & \\
\hline
\end{tabular}

Table 5. Scenarios for irrigated area growth and crop intensity change.

\begin{tabular}{lrrr}
\hline & $\begin{array}{r}\text { Low } \\
\text { growth } \\
(\mathrm{LG})\end{array}$ & $\begin{array}{r}\text { Medium } \\
\text { growth } \\
(\mathrm{MG})\end{array}$ & $\begin{array}{r}\text { High } \\
\text { growth } \\
(\mathrm{HG})\end{array}$ \\
\hline Irrigated area growth $\left(\% \mathrm{yr}^{-1}\right)$ & 0.06 & 0.30 & 0.60 \\
Crop intensity change $\left(\% \mathrm{yr}^{-1}\right)$ & 0.15 & 0.20 & 0.40 \\
\hline
\end{tabular}

Table 6. Scenarios for irrigation efficiency change.

\begin{tabular}{lrrr}
\hline & $\begin{array}{r}\text { High } \\
\text { efficiency } \\
(\mathrm{HE})\end{array}$ & $\begin{array}{r}\text { Medium } \\
\text { efficiency } \\
(\mathrm{ME})\end{array}$ & $\begin{array}{r}\text { Low } \\
\text { efficiency } \\
\text { (LE) }\end{array}$ \\
\hline $\begin{array}{l}\text { Irrigation } \\
\text { efficiency change } \\
\left(\% \mathrm{yr}^{-1}\right)\end{array}$ & 0.30 & 0.15 & 0.0 \\
\hline
\end{tabular}

specified and may be impossible to acquire. The results of our literature review imply that clear mechanisms linking the growth of irrigation and socio-economic factors are not yet fully developed. Thus, arbitrariness cannot be completely excluded when developing an irrigation scenario.

\subsection{Industrial and municipal water withdrawal}

Industrial and municipal water withdrawals account for 18 and $12 \%$ of the total global water withdrawal, respectively (FAO, 2011). Nevertheless their importance, the available global scenarios is limited.

Some key earlier studies projecting future potential industrial water demand are summarized here. Alcamo et al. (2003a) developed a regression model for industrial water withdrawal. Their model is expressed as a multiple regression model using explanatory variables of electricity production and per capita GDP. Shen et al. (2008) developed a similar model but their model has no need for model parameters because of some strong assumptions. Their model explained industrial water withdrawal by electricity production, total primary energy, and GDP. Some recent studies have subdivided industrial water into manufacturing water and electricity production water. Vassolo and Döll (2005) developed separate global maps of thermal power cooling water and manufacturing water use for the period around 1995. Voß and
Table 7. Scenarios for industrial water intensity change $\left(\mathrm{m}^{3} \mathrm{yr}^{-2}\right.$ $\mathrm{MWh}^{-1}$ ).

\begin{tabular}{lrrr}
\hline & $\begin{array}{r}\text { High } \\
\text { efficiency } \\
(\text { HE) }\end{array}$ & $\begin{array}{r}\text { Medium } \\
\text { efficiency } \\
(\mathrm{ME})\end{array}$ & $\begin{array}{r}\text { Low } \\
\text { efficiency } \\
(\mathrm{LE})\end{array}$ \\
\hline $50 \leq \mathrm{i}_{\text {ind }}$ & -2.5 & -1.2 & -0.6 \\
$10 \leq \mathrm{i}_{\text {ind }}<50$ & -0.7 & -0.35 & 0 \\
$i_{\text {ind }}<10$ & -0.2 & 0 & 0 \\
\hline
\end{tabular}

Flörke (2010) and Flörke et al. (2013) proposed a modeling framework to estimate the use of both nationwide manufacturing water and thermal power cooling water, and Flörke and Eisner (2011) calculated this forward to 2050 under the SRES A2 and B1 scenarios. Hayashi et al. (2012) proposed a new type of model that accumulated sector-wise potential industrial water demand. All of these earlier studies estimated model parameters from the historical record. The study of Flörke and Eisner (2011) was an exception in that two different parameters were used to contrast the concepts underpinning two scenarios. Table 3 summarizes earlier modeling studies of industrial water withdrawal.

In many cases, a future potential municipal water demand scenario has been developed together with an industrial scenario. Alcamo et al. (2003a) developed a multiple regression model using explanatory variables of population and GDP per capita. Shen et al. (2008), Voß et al. (2009), and Flörke and Eisner (2011) developed regression models for municipal water. Earlier attempts to model municipal water withdrawal are summarized in Table 4.

Alcamo et al. (2003a) demonstrated that their models successfully reproduced historical time series of industrial and municipal water withdrawal. However such regression modeling has typically encountered two key problems. First, sufficient amounts of reliable data are essential for the estimation of model parameters, although published historical time series of water withdrawals are limited for many countries. Because the relevant parameters are highly variable among countries, transferring data from one country to another is not practical. Second, estimated model parameters represent historical relationships between industrial and municipal water withdrawals and socio-economic factors. It is not clear whether maintaining these parameters throughout the $21 \mathrm{st}$ century is a valid approach under the scenarios of both the 
SRES and SSPs, because they depict substantially different future conditions. For example, two socio-economic scenarios are available for countries with a similar population and GDP, but with different underpinning concepts: one depicts a less resource-intensive future and the other depicts the opposite. If a common regression model is used for these scenarios, the resulting water use scenarios are similar. However, this seems incompatible with the different underpinning concepts of each scenario. Therefore, new types of models are required that better represent the different underpinning concepts of each scenario.

\section{Model development}

\subsection{Irrigation scenario}

\subsubsection{Available information}

In Sect. 3.1, we reviewed recent global hydrological models (including H08) and determined that five variables are required to estimate potential irrigation water demand: the crop-specific potential evaporation $E_{\text {pot }}$, the effective precipitation $P_{\text {eff }}$, the irrigated area $A_{\text {irg }}$, the crop intensity $i_{\text {irg }}$, and the irrigation efficiency $e_{\text {irg }}$. Among these variables, $E_{\text {pot }}$ and $P_{\text {eff }}$ are calculated by the hydrological models using climate scenarios. The remaining three factors are basic boundary conditions of models and must be prepared. It is beyond the scope of this paper to develop a process-based model for $A_{\text {irg }}$, $i_{\text {irg }}$, and $e_{\text {irg }}$ because it is difficult to even specify the key factors controlling the mechanisms of irrigation expansion. Therefore, we used the scenarios adopted in the five previous studies discussed in the previous section (Rosegrant et al., 2002; Bruinsma, 2003; Alcamo et al., 2005; de Fraiture et al., 2007; and Rosegrant et al., 2009).

\subsubsection{Model}

Here we take simplistic assumptions for developing scenarios for $A_{\mathrm{irg}}, i_{\mathrm{irg}}$, and $e_{\mathrm{irg}}$. We assumed $A_{\mathrm{irg}}, i_{\mathrm{irg}}$, and $e_{\mathrm{irg}}$ are expressed as a power of time:

$$
\begin{aligned}
& A_{\text {irg }, t}=\left(1+r_{\text {area }}\right)^{t-t_{0}} A_{\text {irg, } t_{0}} \\
& i_{\text {irg }, t}=\left(1+r_{\text {int }}\right)^{t-t_{0}} i_{\text {irg }, t_{0}} \\
& e_{\text {irg }, t}=\left(1+r_{\text {eff }}\right)^{t-t_{0}} e_{\text {irg, } t_{0}}
\end{aligned}
$$

where $r_{\text {area }}, r_{\text {int }}$, and $r_{\text {eff }}$ are the annual growth ratios of the irrigated area, crop intensity, and irrigation efficiency. The subscript $t$ denotes time (year), and $t_{0}$ indicates the base year (2000).

Equation (1) is applied to each grid cell. This means that $A_{\text {irg }}$ simply increases where irrigated area exists at the base year, not explicitly taking the availability of suitable land within a grid cell into account. These problems could be resolved if we evaluated the suitability of new irrigation projects in the world, but it is beyond the scope of this study. Similarly, because it is difficult to set the technical upper bound of irrigation efficiency in the future, we assumed $e_{\text {irg }}$ of Eq. (3) could reach 1.0. The settings for crop type and irrigation practices are shown in the accompanying paper (Hanasaki et al., 2013).

\subsubsection{Intermediate irrigation scenario}

Here we propose an intermediate irrigation scenario that is independent of the SSPs. On the basis of Table 2, we set three options for $r_{\text {area }}$ and $r_{\text {int }}$ (Table 5) and $r_{\text {eff }}$ (Table 6). Two were taken from the highest and lowest values among the five reports we reviewed, and the remaining was an intermediate value. We used a global map of $A_{\text {irg }}$ at the base year (2000) provided by Siebert et al. (2005) and $i_{\text {irg }}$ and $e_{\text {irg }}$ values were taken from Döll and Siebert (2002). All data were converted into a $0.5^{\circ} \times 0.5^{\circ}$ grid, the standard spatial resolution of $\mathrm{H} 08$. Equations (1)-(3) were applied uniformly on a global basis for all three options of $r_{\text {area }}, r_{\text {int }}$, and $r_{\text {eff }}$, respectively. Note that some of the five reports expressed regional differences in $r_{\text {area }}$, but for consistency among scenarios, we assumed that the ratio is constant all over the world except for one special case that is described later. We also assumed that the ratio is constant throughout the century, because neither transient projections nor projections beyond 2050 were available in the five reports, with the exception of Alcamo et al. (2005).

\subsection{Industrial water}

\subsubsection{Available data and historical trends}

For modeling industrial water withdrawal, we revisited the historical records of AQUASTAT (FAO, 2011). AQUASTAT details the total industrial water withdrawals for 200 countries during the period 1960-2010 at five-year intervals. Although data for the period around 2000 were available for most countries, other periods were often missing. We did not interpolate these missing values. We selected 16 nations for which a record for longer than $20 \mathrm{yr}$ was available. The total number of data records used here ranged from three to seven for each country. We then collected electricity production data (World Bank, 2009) for these countries. In some countries, particularly in the developed world, national statistics on water use were available from sources other than AQUASTAT, which is potentially useful. However, we only used AQUASTAT because of its high global coverage, including developing countries, which is critically important for this study.

Figure 4 shows the relationship between time (year) and industrial water intensity $\left(\mathrm{m}^{3} \mathrm{yr}^{-1} \mathrm{MWh}^{-1}\right)$ which is defined as industrial water withdrawal per unit of electric production. The nations were categorized into three categories: (A) intensity greater than $50 \mathrm{~m}^{3} \mathrm{yr}^{-1} \mathrm{MWh}^{-1}$, namely, Belgium, 

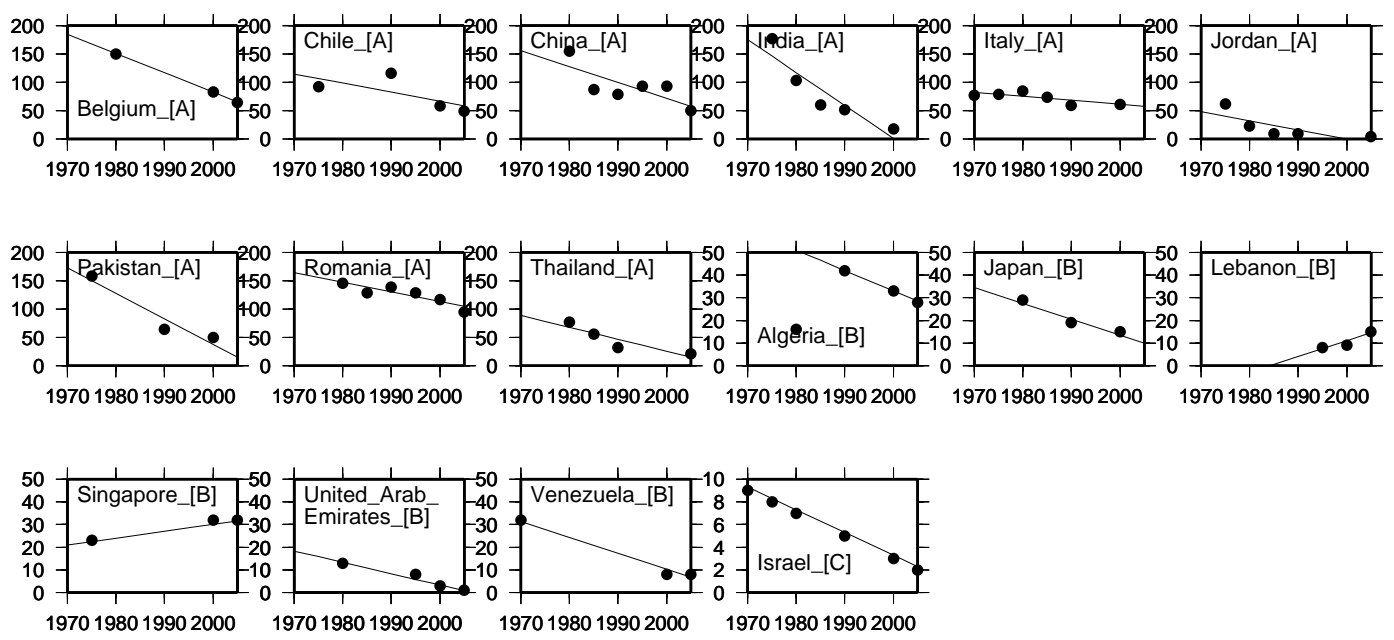

Fig. 4. Historical records of national industrial water intensity (plot) and regressions (line) $\left(\mathrm{m}^{3} \mathrm{yr}^{-1} \mathrm{MWh}^{-1}\right)$.
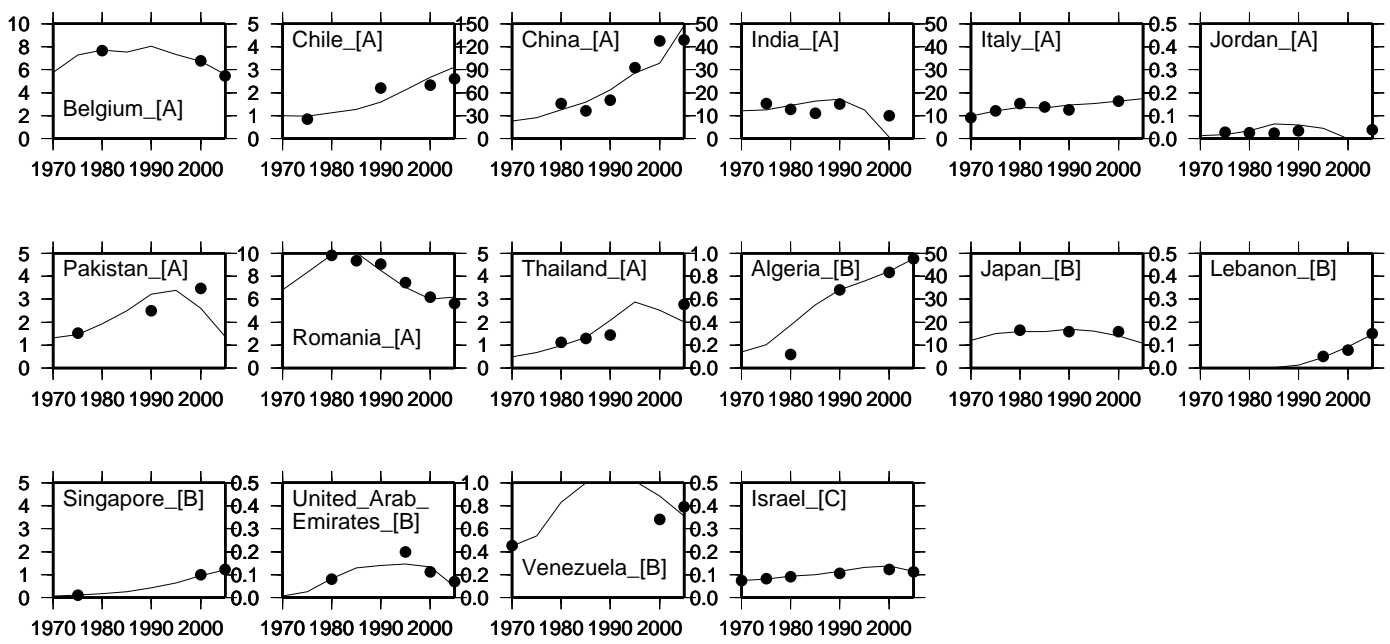

Fig. 5. Historical records of national industrial water withdrawal (plot) and estimations with Eq. (4) (line) $\left(\mathrm{km}^{3} \mathrm{yr}^{-1}\right)$.

Chile, China, India, Italy, Pakistan, Romania, and Thailand; (B) intensity not greater than 50 but greater than $10 \mathrm{~m}^{3} \mathrm{yr}^{-1}$ $\mathrm{MWh}^{-1}$, namely, Algeria, Japan, Jordan, Lebanon, Singapore, UAE, and Venezuela; and $(\mathrm{C})$ intensity not greater than $10\left(\mathrm{~m}^{3} \mathrm{yr}^{-1} \mathrm{MWh}^{-1}\right)$, Israel only. Two characteristics are apparent from Fig. 4. First, there is a linear decreasing trend in industrial water intensity in all nations except Lebanon and Singapore. Second, the range of slopes within each category is relatively small: from -5.8 to -0.7 for Category A countries, from -1.6 to +0.7 for Category $\mathrm{B}$, and -0.2 for Category $\mathrm{C}\left(\mathrm{m}^{3} \mathrm{yr}^{-2} \mathrm{MWh}^{-1}\right)$. In contrast, there were substantial differences in industrial water intensity (see the vertical axes of Fig. 4).

\subsubsection{Model}

Because Fig. 4 clearly shows a linear decreasing trend in industrial water intensity, we assumed that industrial water withdrawal $(I)\left(\mathrm{m}^{3} \mathrm{yr}^{-1}\right)$ can be expressed as

$I=\mathrm{ELC} \times\left(i_{\text {ind,to }}+s_{\text {ind,cat }} \times\left(t-t_{0}\right)\right)$

where ELC is electricity production (MWh), $t_{0}$ is the base year (2005), $i_{\text {ind, } t 0}$ is the industrial water intensity $\left(\mathrm{m}^{3} \mathrm{yr}^{-1}\right.$ $\mathrm{MWh}^{-1}$ ) at $t_{0}$, and $s_{\text {ind,cat }}$ is the slope. The subscript cat indicates the three categories shown above. Industrial water withdrawal includes both manufacturing use and energy production. Therefore, $i_{\text {ind }, t 0}$ could be substantially higher if it included hydropower generation.

To confirm the validity of Eq. (4), $i_{\text {ind, } t 0}$ and $s_{\text {ind,cat }}$ were estimated for all 16 countries. $i_{\text {ind }, t 0}$ was estimated using the ELC and $I$ for the base year. $s_{\text {ind,cat }}$ was estimated using the least-square method because of the clear linear relationship as shown in Fig. 4. Figure 5 presents a historical projection of industrial water withdrawal. Even for a very simple model, historical trends are well captured. 
(a) Industrial water

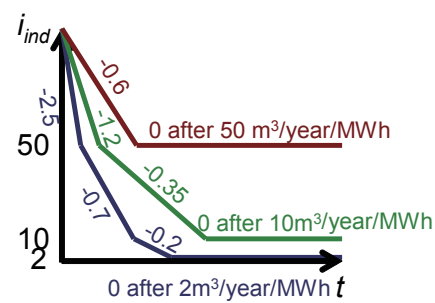

(b) Municipal water

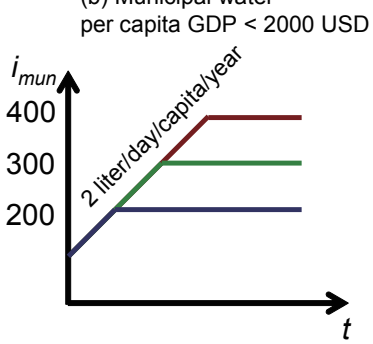

(c) Municipal water

2000 USD • per capita GDP

$i_{m}$

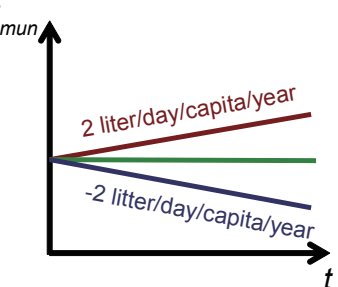

Fig. 6. Schematic diagram of intermediate water use scenarios for (a) industrial water withdrawal, (b) municipal water withdrawal for countries with per capita GDP < 2000 USD, and (c) for countries with 2000 USD $\leq$ per capita GDP. Blue for High Efficiency, green for Medium Efficiency, and red for Low Efficiency scenario.
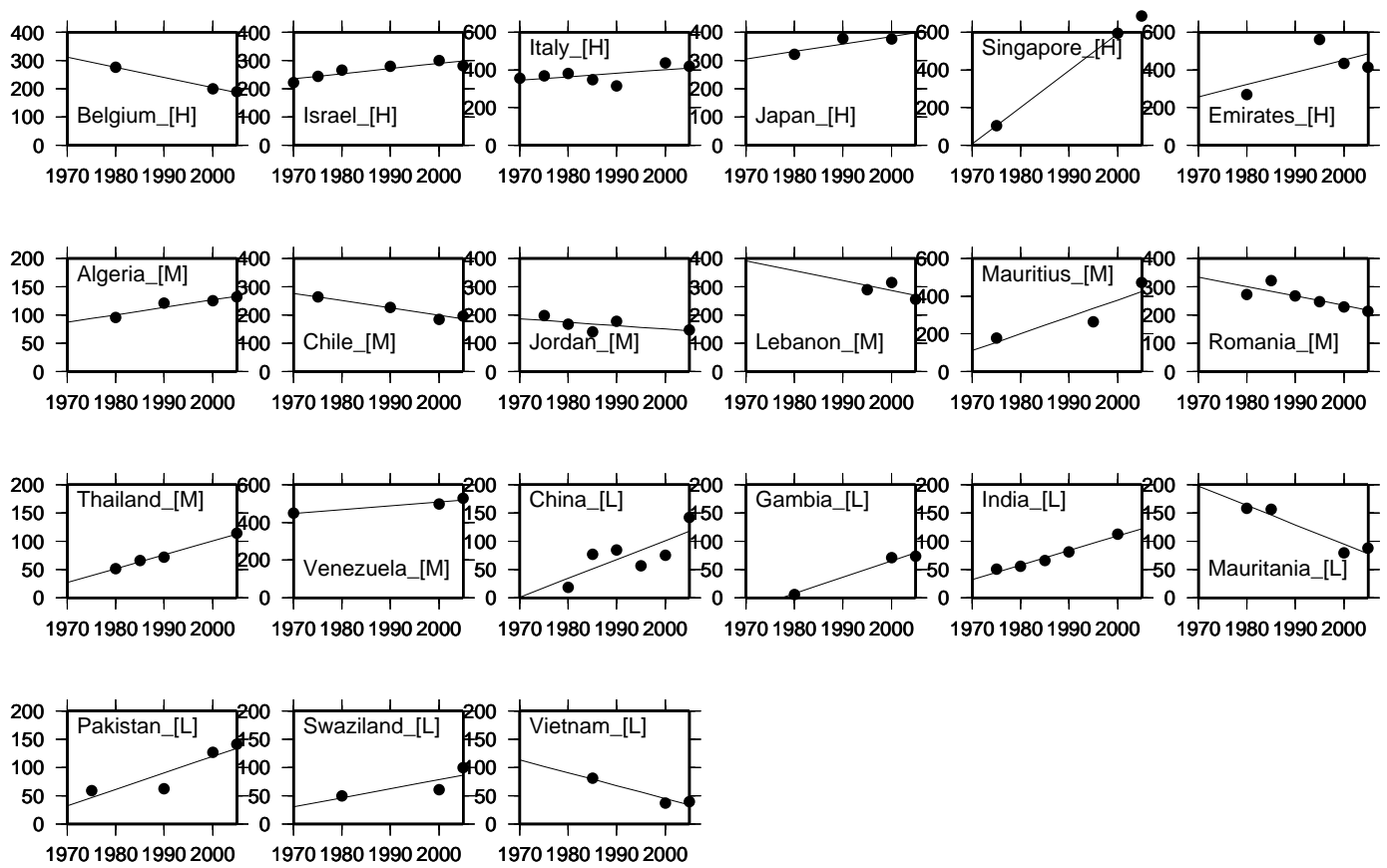

Fig. 7. Historical records of national municipal water intensity (plot) and regressions (line) $\left(\mathrm{L} \mathrm{day}^{-1}\right.$ person $\left.^{-1}\right)$.

\subsubsection{Intermediate water use scenario}

The model expressed in Eq. (4) needs one coefficient, $s_{\text {ind,cat }}$. This could be calibrated for each nation if a historical time series was available, and the model could be used for a future scenario analysis if we assume that the coefficient does not vary with time. However, for many countries of the world, time series records are lacking and calibration is difficult; this causes problems when we apply Eq. (4) on a global basis. Moreover, as discussed in the previous section, each SSP represents very different conditions, which strongly implies that $s_{\text {ind,cat }}$ would also vary.

Here we propose an intermediate industrial water use scenario. A schematic diagram is shown in Fig. 6a. We considered three sets of $s_{\text {ind,cat }}$ as shown in Table 7. The High Efficiency scenario (HE) assumes that all countries in the world can be represented by the median $s_{\text {ind,cat }}$ of the countries in each category. For example, the median $s_{\text {ind,cat }}$ for category A is close to the historical path of Thailand and China, the median $s_{\text {ind,cat }}$ for category B is close to Japan, and the median $s_{\text {ind,cat }}$ for category $\mathrm{C}$ is identical to Israel. We set the minimum $i_{\text {ind }}$ at $2 \mathrm{~m}^{3} \mathrm{yr}^{-1} \mathrm{MWh}^{-1}$. Our analyses indicated that there are nations displaying more rapid changes in $s_{\text {ind,cat }}$ but when this was applied globally including the major industrial countries, the results were unrealistic. We judged that the median of each category could be used in the HE because Thailand, China, Japan, and Israel can be considered to be representative of major industrial countries. In the Medium Efficiency scenario (ME), $s_{\text {ind,cat }}$ is half of that in the HE. In the ME scenario, we set the minimum $i_{\text {ind }}$ at $10 \mathrm{~m}^{3} \mathrm{yr}^{-1} \mathrm{MWh}^{-1}$. In the Low Efficiency scenario (LE), $s_{\text {ind,cat }}$ is a quarter of that in the HE. The minimum $i_{\text {ind }}$ 

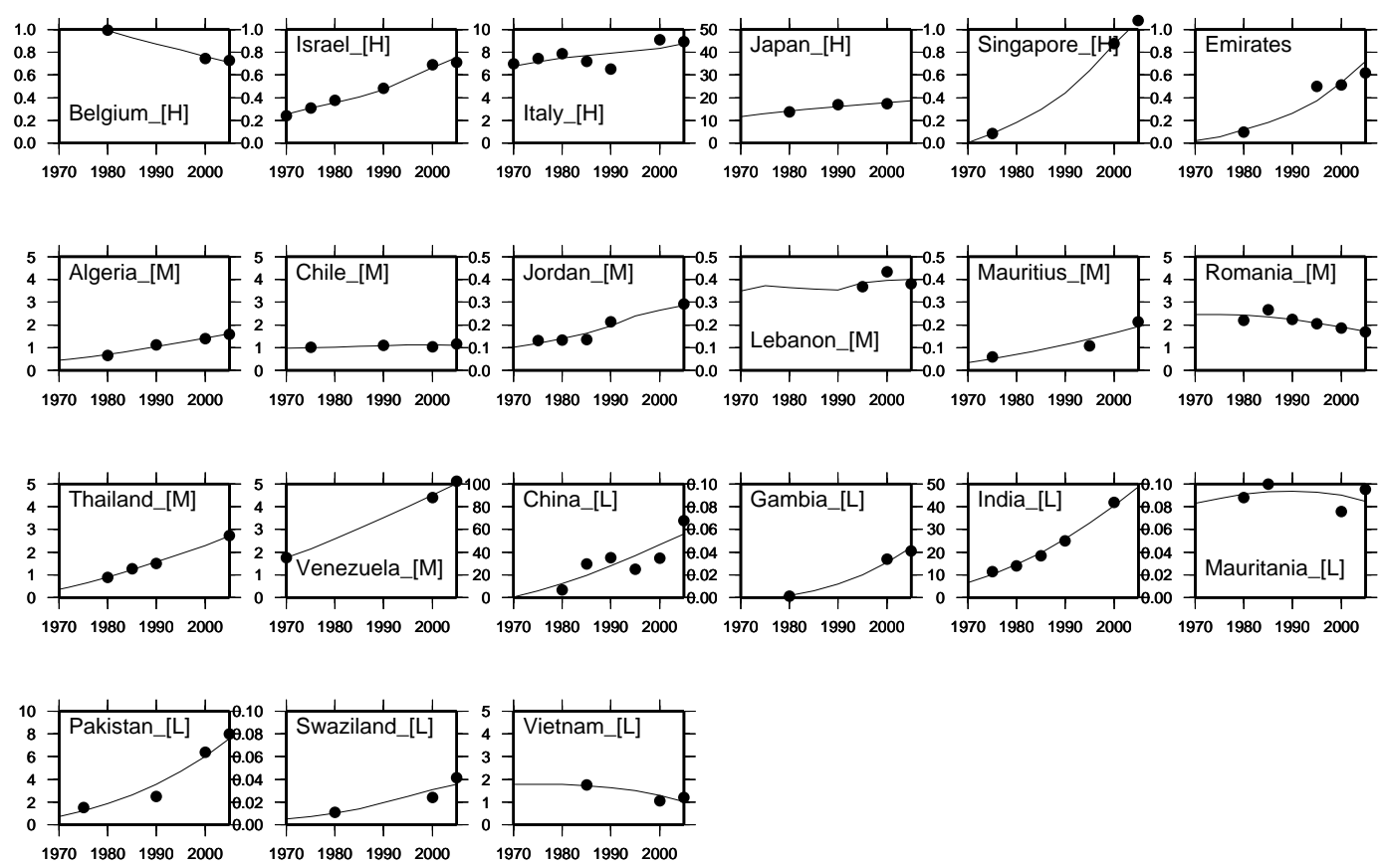

Fig. 8. Historical records of national municipal water withdrawal (plot) and estimations with Eq. (5) (line) $\left(\mathrm{km}^{3} \mathrm{yr}^{-1}\right)$.

Table 8. Scenarios for municipal water intensity change $\left(\mathrm{L} \mathrm{person}^{-1} \mathrm{day}^{-1} \mathrm{yr}^{-1}\right)$.

\begin{tabular}{lllll}
\hline & & High efficiency $(\mathrm{HE})$ & Medium efficiency (ME) & Low efficiency (LE) \\
\hline per capita GDP $<2000$ USD & $200 \leq i_{\text {mun }}$ & $-2\left(200 \leq i_{\text {mun }}\right)$ & 0 & $2\left(i_{\text {mun }}<600\right)$ \\
& $i_{\text {mun }}<200$ & $2\left(i_{\text {mun }}<200\right)$ & $2\left(i_{\text {mun }}<300\right)$ & $2\left(i_{\text {mun }}<400\right)$ \\
2000 USD $\leq$ per capita GDP & & $-2\left(200 \leq i_{\text {mun }}\right)$ & 0 & $2\left(i_{\text {mun }}<800\right)$ \\
\hline
\end{tabular}

was set at $50 \mathrm{~m}^{3} \mathrm{yr}^{-1} \mathrm{MWh}^{-1}$. If $i_{\text {ind, } t 0}$ was already below the minimum $i_{\text {ind }}$, we assumed that the $i_{\text {ind }}$ of the country in question would be unchanged throughout the century.

This model could be applied globally because $i_{\text {ind, } t 0}$ and the category of the base year could be calculated from the national industrial water withdrawal data from AQUASTAT and the electricity production data of the World Bank (2009). As mentioned above, AQUASTAT does not always include withdrawal data for the exact year of 2005. In such cases, data for the nearest year were used. Electricity production in the future was provided by the AIM-SSPs for 12 regions. Because no further information was available, the rate of change was assumed to be uniform across the countries in a region. Equation (4) was applied for each nation. To make the results grid-based, we assumed that industrial water withdrawal is geographically distributed proportionally to the population. Earlier studies proposed the usage of different socio-economic drivers, for instance urban population (Alcamo et al., 2003a), city nighttime lights (Vassolo and Döll, 2005), and urban area extent (Otaki et al., 2008). These methods have advantages but were not adopted in this study because it was difficult to obtain future scenarios for drivers. We used global population distribution data from the Center for International Earth Science Information Network (CIESIN) and the Centro Internacional de Agricultura Tropical (CIAT) (2005).

\subsection{Municipal water model}

\subsubsection{Available data and historical trends}

Earlier studies have developed municipal water models in a manner similar to their industrial water models and, thus, have faced similar problems to those discussed above. We also revisited the historical trends of municipal water withdrawal from AQUASTAT (FAO, 2011). Figure 7 shows the historical trend of municipal water withdrawal per person for 21 countries where a time series of longer than $20 \mathrm{yr}$ was available. As for industrial water, the number of data records used for each country ranged from three to seven. We then obtained population data (United Nations, 2011) and the GDP in 2000 USD (World Bank, 2009) for these countries. The countries were sorted into three categories, high-income nations (10 000 USD $<$ per capita GDP, denoted H), medium-income nations (2000 USD < per capita GDP 
Table 9. Parameters for Eqs. (1)-(5).

\begin{tabular}{lrrrrr}
\hline & SSP1 & SSP2 & SSP3 & SSP4 & SSP5 \\
\hline Irrigated area growth $\left(\% \mathrm{yr}^{-1}\right)$ & 0.06 & 0.30 & 0.60 & 0.06 & 0.60 \\
Crop intensity change $\left(\% \mathrm{yr}^{-1}\right)$ & 0.15 & 0.20 & 0.40 & 0.15 & 0.40 \\
Improvement in irrigation water efficiency $\left(\% \mathrm{yr}^{-1}\right)$ & 0.30 & 0.15 & 0.00 & 0.00 & 0.30 \\
Improvement in industrial water efficiency (Table 7) & $\mathrm{HE}$ & $\mathrm{ME}$ & $\mathrm{LE}$ & $\mathrm{MIX}$ & $\mathrm{HE}$ \\
Improvement in municipal water efficiency (Table 8) & $\mathrm{HE}$ & $\mathrm{ME}$ & $\mathrm{LE}$ & $\mathrm{MIX}$ & $\mathrm{HE}$ \\
\hline
\end{tabular}

MIX indicates HE in OECD countries and LE in non-OECD countries.

$\leq 10000$ USD, M), and low-income nations (per capita GDP $\leq 2000$ USD, L).

We analyzed the trend of per capita water withdrawal for each nation. We found that per capita water withdrawal varied significantly, for example from 33.7 to $688.2 \mathrm{~L} \mathrm{day}^{-1}$ person $^{-1}$ in 2000 . The range of values was slightly reduced to between 33.7 and $518.4 \mathrm{Lday}^{-1}$ person $^{-1}$ when we excluded countries with a population of less than 10 million. This suggests that it is difficult to obtain general rules that are applicable to all countries in the world. In contrast, the range of slopes was much closer among nations being between -3.6 and 19.5 $\mathrm{L} \mathrm{day}^{-1}$ person ${ }^{-1} \mathrm{yr}^{-1}$ (Fig. 7). If nations with a population less than 10 million were excluded, the range of the slope was between -3.6 and $3.3 \mathrm{~L} \mathrm{day}^{-1}$ person $^{-1} \mathrm{yr}^{-1}$. Figure 7 reveals the central problem in municipal water modeling: there is no clear relationship between the volume of water withdrawal and per capita GDP among nations, or its increasing/decreasing trend. For example, with the medium-income nations, an increasing trend can be observed for some countries (Mauritius and Venezuela), whereas for others stabilization and a decreasing trend are apparent (Chile and Jordan). There are also nations using more than $400 \mathrm{~L} \mathrm{day}^{-1}$ capita $^{-1}$ (Mauritius and Venezuela) and less than $200 \mathrm{~L} \mathrm{day}^{-1}$ capita $^{-1}$ (Algeria, Thailand). Here we found two common characteristics among the 21 countries. First, in the nations with less than 2000 USD per capita GDP, municipal water withdrawal tends to be increasing (Mauritania and Vietnam are exceptions). Second, water withdrawal did not stabilize much below $200 \mathrm{Lday}^{-1}$ capita $^{-1}$ in any nation.

\subsubsection{Model}

As with industrial water withdrawal, we modeled municipal water withdrawal $\left(M ; \mathrm{m}^{3} \mathrm{yr}^{-1}\right)$ as

$M=\mathrm{POP} \times\left(i_{\text {mun,to }}+s_{\text {mun,cat }} \times\left(t-t_{0}\right)\right) \times 0.365$

where POP is the population (number of individuals), $i_{\text {mun }, t 0}$ is the municipal water intensity for the base year $\left(\mathrm{L} \mathrm{day}^{-1}\right.$ person $\left.^{-1}\right), s_{\text {mun,cat }}$ is slope, and the multiplier 0.365 is applied for unit conversion.

Historical trends of municipal water withdrawal were estimated using Eq. (5) and are shown in Fig. 8. This indicates that Eq. (5) reproduces the historical variation of municipal
Table 10. Total global withdrawal-based potential industrial water demand $\left(\mathrm{km}^{3} \mathrm{yr}^{-1}\right)$.

\begin{tabular}{rrrrrr}
\hline & SSP1 & SSP2 & SSP3 & SSP4 & SSP5 \\
\hline 2025 & 853 & 1169 & 1435 & 1087 & 1000 \\
2055 & 519 & 1437 & 1895 & 1116 & 808 \\
2085 & 246 & 1259 & 1714 & 851 & 521 \\
\hline
\end{tabular}

Table 11. Total global withdrawal-based potential municipal water demand $\left(\mathrm{km}^{3} \mathrm{yr}^{-1}\right)$.

\begin{tabular}{rrrrrr}
\hline & SSP1 & SSP2 & SSP3 & SSP4 & SSP5 \\
\hline 2025 & 544 & 598 & 631 & 583 & 549 \\
2055 & 622 & 822 & 935 & 780 & 645 \\
2085 & 573 & 973 & 1280 & 967 & 619 \\
\hline
\end{tabular}

water well if the slope $\left(s_{\text {mun,cat }}\right)$ and interval $\left(i_{\text {mun,t } t 0}\right)$ are statistically estimated for each nation.

\subsubsection{Intermediate water use scenario}

Like for industrial water withdrawal, we developed an intermediate municipal water use scenario. Schematic diagrams are shown in Fig. 6b-c. We set three municipal water scenarios as shown in Table 8. In the HE scenario municipal water withdrawal decreases toward per capita municipal water use of $200 \mathrm{~L} \mathrm{day}^{-1}$ globally. In the LE scenario municipal water withdrawal increases, and in the ME scenario it remains constant at the current level. Because we found the magnitude of slope to be between -3.6 and 3.3 $\mathrm{L}_{\text {person }}{ }^{-1} \mathrm{yr}^{-1}$ for nations with a population of more than 10 million, we set $s_{\text {dom,cat }}$ for $\mathrm{HE}$ and $\mathrm{LE}$ at -2 and $2 \mathrm{~L}_{\text {person }}{ }^{-1} \mathrm{day}^{-1} \mathrm{yr}^{-1}$, respectively. For countries with a per capita GDP below 2000 USD, $s_{\text {dom,cat }}$ grows at the rate of $2 \mathrm{~L}_{\text {person }}{ }^{-1}$ day $^{-1} \mathrm{yr}^{-1}$ in all scenarios because we found that no country stabilized below this level. The increase in per capita water use continues until it reaches 200,300 , and $400 \mathrm{~L}_{\text {person }}{ }^{-1}$ day $^{-1}$ for $\mathrm{HE}, \mathrm{ME}$, and LE, respectively. Note that $200 \mathrm{~L}_{\text {person }}{ }^{-1}$ day $^{-1}$ is the same level as is currently withdrawn in nations such as Belgium and Chile and reducing this would be a challenging but realistic target. For example, Singapore is targeting domestic 

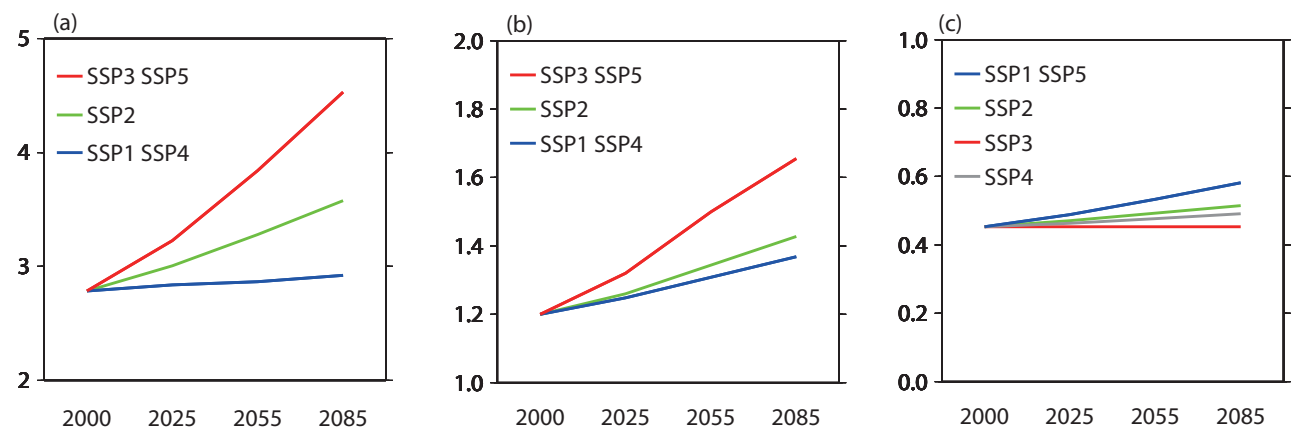

Fig. 9. Scenarios of (a) global total irrigated area $\left(10^{6} \mathrm{~km}^{2}\right)$, (b) global mean crop intensity (crops yr ${ }^{-1}$ ), (c) global mean irrigation efficiency $(-)$.

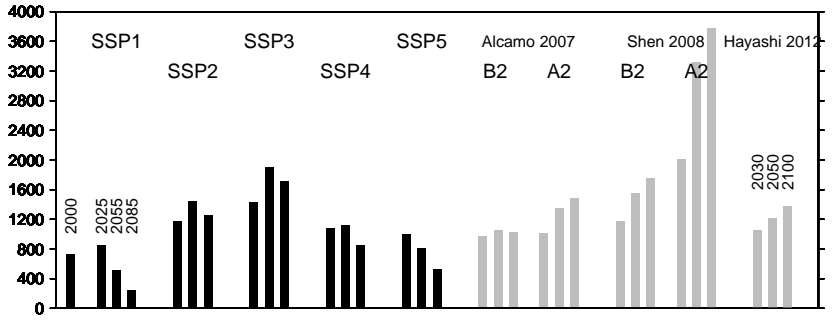

Fig. 10. Scenarios for total global withdrawal-based potential industrial water demand $\left(\mathrm{km}^{3} \mathrm{yr}^{-1}\right)$.

water use at $140 \mathrm{~L}_{\text {person }}{ }^{-1}$ day $^{-1}$ (PUB Singapore's National Water Agency, 2012).

This model can be applied globally because $i_{\text {mun, } t 0}$ and the category of the base year can be calculated for all countries from the national municipal water withdrawal data of AQUASTAT, UN population data (2011), and GDP data from the World Bank (2009). As with industrial water, municipal water was geographically distributed at a $0.5^{\circ} \times 0.5^{\circ}$ spatial resolution, using CIESIN and CIAT (2005).

\section{Linking water use scenarios and SSPs}

We developed models for irrigated area, crop intensity, irrigation efficiency, industrial and municipal water withdrawal. Each model has one parameter. By setting three options for each parameter (Tables 5, 6, 7, 8), we have developed three intermediate water use scenarios. In the next stage, we ensured their compatibility with the SSPs. We focused on the narrative scenarios of the SSPs (O'Neill et al., 2012), which are summarized in Table 1. The key items we focused on are technology change and environmental consciousness.

\subsection{Interpretation of SSPs for irrigated area and crop intensity}

It is known that undeveloped areas that are suitable for new irrigation projects are limited (Bruinsma, 2003). This im- plies that the rapid expansion of irrigated area may be accompanied by environmental degradation. An increase in the use of irrigation water imposes further alterations of river and groundwater systems, which are likely to impact ecosystems. Therefore, the general environmental consciousness of society is reflected in the possible future expansion of irrigation, with a possible restriction in expansion when environmental consciousness is high. Table 1 indicates that environmental consciousness is considered to be high for SSP1, medium for SSP2, and low for SSP3 and SSP5. The environmental consciousness for SSP4 is not clearly identified in its narrative scenario, but the pathway mentions low crop yields in small-scale farming, which implies less pressure toward irrigation for the majority of cropland. Therefore, SSP3 and SSP5 would be more likely to result in an expansion of the irrigated area, whereas SSP1 and SSP4 would be less likely. The situation for SSP2 would be intermediate between the two groups. Therefore, we assigned High Growth in Table 5 to SSP3 and SSP5, Medium Growth to SSP2, and Low Growth to SSP1 and SSP4. The combination is summarized in Table 9 and illustrated in Fig. 1b.

\subsection{Interpretation of irrigation efficiency and changes in industrial and municipal water intensities}

Irrigation efficiency and changes in industrial and municipal water intensities are considered to be dependent on the technology scenario of the SSPs in this study. Table 1 indicates that technology is high for SSP1 and SSP5, medium for SSP2, and low for SSP3. The narrative and quantitative scenarios of SSP4 indicate that technology is high in developed countries but low in developing countries. Additionally, because the adaptation challenge of SSP4 is large, it can be anticipated that water efficiencies in developing countries will not improve much, and their water intensity will remain high. This implies that SSP1, SSP5, and SSP4 in developed countries would be more efficient, whereas SSP3 and SSP4 in developing countries would be less efficient. SSP2 would be intermediate between the two groups. Therefore, from Tables 6-8 we assigned High Efficiency to SSP1, SSP5, and 


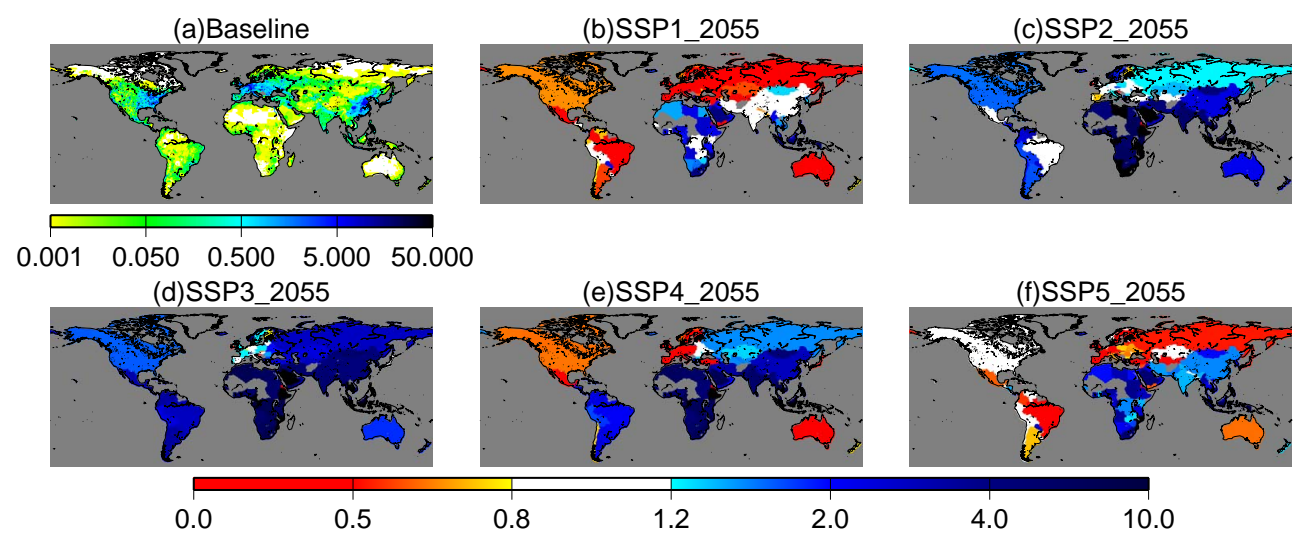

Fig. 11. Global distribution of withdrawal-based potential industrial water demand. (a) Baseline year $($ circa 2000$)\left(\mathrm{m}^{3} \mathrm{~s}^{-1}\right),(\mathbf{b}-\mathbf{f})$ Change (ratio) from the baseline year for SSP1-5 in 2055.

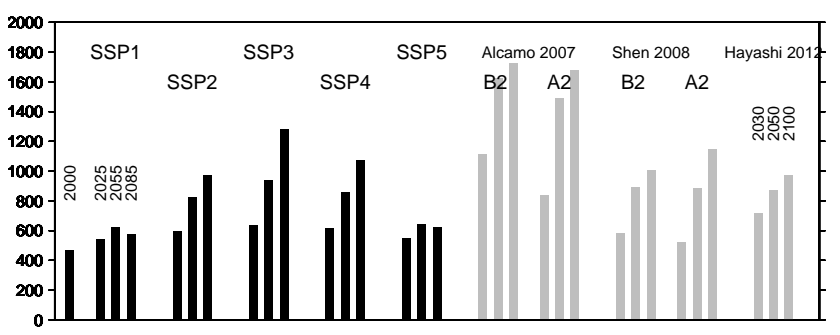

Fig. 12. Scenarios of total global withdrawal-based potential municipal water demand $\left(\mathrm{km}^{3} \mathrm{yr}^{-1}\right)$.

SSP4 in developed countries, Medium Efficiency to SSP2, and Low Efficiency to SSP3 and SSP4 in developing countries. We defined developed countries as members of the Organization for Economic Co-operation and Development (OECD) as of 2005 and developing countries as other countries. The combination is illustrated in Fig. 1c.

\section{Results and discussion}

\subsection{Irrigation scenarios}

Figure 9 shows the irrigated area, crop intensity, and irrigation efficiency scenarios. Because these scenarios are expressed by a simple power law (Eqs. 1-3), they display simple relationships, but they highlight clear differences in the narrative scenarios of each SSP. Potential irrigation water demand is reported in the accompanying paper (Hanasaki et al., 2013), as global hydrological simulations are required for its estimation. This study only sets up the boundary conditions of such simulations.

The irrigation scenario was developed under the following assumptions and limitations. First, it is beyond the scope of this study to develop in-depth food and agricultural scenarios consistent with the SSPs. In reality, the growth of irrigation may reflect increases in food demand or price, invest- ments in the agricultural sector, improved agricultural technology (e.g. yield increases), land use changes, and other factors (Faurès et al., 2007). The latest socio-economic scenarios sometimes include quantitative scenarios that cover total food production and the area under cropland (e.g. van Vuuren et al., 2011), but setting up irrigation scenarios from these scenarios is still difficult because allocating food production into rainfed and irrigated agriculture systems remains challenging. Further study is required for the development of more consistent scenarios. Second, all scenarios in this study assume that the irrigated area increases in the future, based on the five agriculture and food reports we reviewed (Rosegrant et al., 2002, 2009; Bruinsma, 2003; Alcamo et al., 2005; de Fraiture et al., 2007). However, some earlier studies have assumed no change or a decrease in irrigation in the future. For example, Alcamo et al. (2007) assumed there would be no growth at all, and Hayashi et al. (2012) assumed a decrease of approximately $0.2 \% \mathrm{yr}^{-1}$ globally. The range of scenarios would be even larger if we adopted these assumptions. Third, the populations assumed in the SSPs and the five reports were different, but no population adjustment was performed in this study. Population would affect the growth of irrigation, although it is not the single dominant factor. Fourth, we extended the period beyond the original reports. For example, Bruinsma (2003) projected toward 2030, but we simply extended to 2100 because of the lack of further information. For SSP3 and SSP5, the total global irrigated area reaches $4.5 \times 10^{6} \mathrm{~km}^{2}$, which slightly exceeds all the land with irrigation potential $\left(4.03 \times 10^{6} \mathrm{~km}^{2}\right.$; Bruinsma, 2003). A continuous expansion of the area under irrigation throughout the century might be an unrealistic assumption because cropland suitable for irrigation is limited. An increase in crop intensity would be more realistic (i.e. multiple cropping is enhanced in the existing irrigated area). This suggests that the combined effect of area growth $r_{\text {area }}$ and the increase in crop intensity $r_{\text {int }}$ would be more robust than for the two individual scenarios. Fifth, regional differences were not included. 


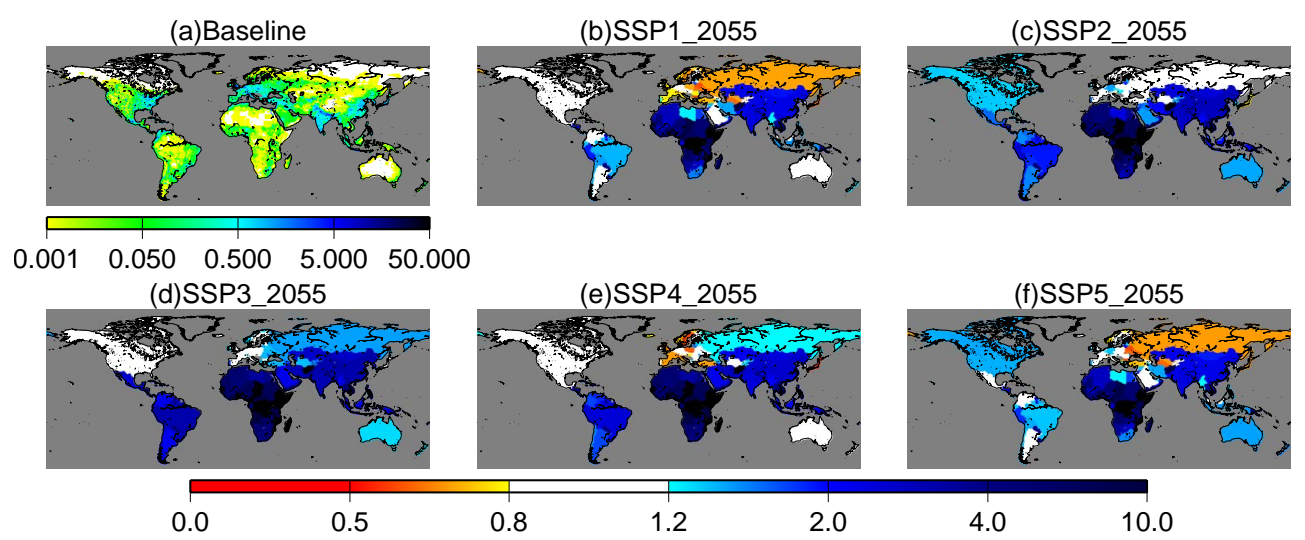

Fig. 13. Global distribution of withdrawal-based potential municipal water demand. (a) Baseline year $($ circa 2000$)\left(\mathrm{m}^{3} \mathrm{~s}^{-1}\right),(\mathbf{b}-\mathbf{f})$ Change (ratio) from the baseline year for SSP1-5 in 2055.

The only exception is $e_{\text {irg }}$ of SSP4, which uses different parameters for OECD countries and non-OECD ones. Sixth, we assumed that the irrigated area only expanded within a grid cell. This assumption fixes the spatial distribution of water use. Areas currently not irrigated continue to be un-irrigated throughout the century. This might lead to an overestimation of water scarcity, particularly in currently heavily irrigated regions, because no extra land would remain for further irrigation expansion.

\subsection{Industrial water scenarios}

Figure 10 and Table 10 show the total global withdrawalbased potential industrial water demand. It highlights the differences in the narrative scenarios of the SSPs. SSP1 and SSP5 indicate large decreases in the total volume of global potential water demand. This is primarily explained by the rapid improvement in volume of industrial water withdrawn per unit electricity production (Table 7). Electricity production increases in the 21st century in both scenarios (Fig. 2c), but the effect of the improvement in efficiency is overwhelming. In SSP2, industrial water is relatively stable throughout the 21 st century, which indicates that improvements in efficiency and the growth of electricity production are compensating for each other.

Figure 11 shows the global distribution of changes in withdrawal-based potential industrial water demand. Note that the changes are shown for individual countries (i.e. the color changes at national boundaries). In SSP1, potential water demand decreases globally, except for countries in Africa. The pattern is quite similar for SSP5, but owing to the larger electricity production, the amount is larger than in SSP1. In SSP2 and SSP3 there are global increases. There is a significant contrast in SSP4. Withdrawal-based potential industrial water demand decreases in OECD countries due to rapid changes in technology. In contrast, there are only moderate increases in non-OECD countries because of the slower rate of technological change.
Figure 10 also shows the withdrawal-based potential industrial water demand scenarios of Alcamo et al. (2007), Shen et al. (2008), and Hayashi et al. (2012). Alcamo et al. (2007) developed a water use scenario for the SRES A2 and B2 scenarios, whereas Shen et al. (2008) used the SRES A1, A2, B1, and B2 scenarios, and Hayashi et al. (2012) used the ALPS-A scenario which is similar to SRES B2. Because the SRES, SSPs, and ALPS-A are different scenarios, direct comparisons do not make sense, but they do indicate the possible range of water withdrawal projections in the 21 st century.

Withdrawal-based potential industrial water demand in SSP2 was close to the scenarios of Alcamo et al. (2007) and Hayashi et al. (2010). This is encouraging because both Alcamo et al. (2007) and Hayashi et al. (2010) estimated their model parameters from historical trends. This approach is compatible with the SSP2 assumption that the typical trends of recent decades will continue. SSP1 and SSP5 are very different, showing decreasing trends. Discussing model feasibility is quite difficult under the current regression modeling framework. Sector- and process-based models are required for better analyses.

The industrial water scenario was developed under the following assumptions and limitations. First, a linear decrease in electricity production per unit of water use $\left(s_{\text {ind,cat }}\right)$ was assumed during the study period. This was confirmed from available historic records (Fig. 5), but it is uncertain how far into the future the observed trend continues. Second, $s_{\text {ind,cat }}$ was assumed to be uniform for each category over the entire world. In reality, potential industrial water demand reflects the different activities of industrial sectors, methods of electricity generation, and water use intensity. These terms have regional differences owing to differences in the stage of technology development. Ideally, a new type of model is needed that explicitly takes these individual factors into account. Hayashi et al. (2012) initiated the development of a sectorwise manufacturing water scenario. Vassolo and Döll (2005), 
Voß et al. (2011), Flörke and Eisner (2011), and Flörke et al. (2013) initiated the development of technology-wise (power generation method and cooling type) thermal power cooling water scenarios. These approaches are promising, but also challenging because they require very detailed global inventories of manufacturing and power generation from the present to the future, including geographical information.

\subsection{Municipal water scenarios}

Figure 12 and Table 11 show the total global withdrawalbased potential municipal water demand. In SSP1, this is projected to be almost constant throughout the 21 st century, because population growth is low and this scenario assumes that all countries move toward a water use level of $200 \mathrm{~L} \mathrm{day}^{-1}$ person $^{-1}$. The other four scenarios show an increase in water use. SSP3 has the largest increase because it has the highest population growth and the largest increase in per capita water use (Table 8). SSP2, SSP4, and SSP5 are intermediates between SSP1 and SSP3, reflecting their population and per capita water use scenarios.

Figure 13 shows the global distribution of changes in withdrawal-based potential municipal water demand. Basically, all scenarios have a similar pattern: increases in developing countries, particularly in Africa. This is easily explained because many of these countries currently fall below the water use level of $200 \mathrm{~L} \mathrm{day}^{-1}$ person $^{-1}$, and therefore, under all scenarios, per capita water withdrawal will increase. Moreover, population increases are expected in these countries.

The range of the total global withdrawal-based potential municipal water demand in the five scenarios for three periods is within the range reported by Alcamo et al. (2007), Shen et al. (2008), and Hayashi et al. (2010). The range of values in SSP1-5 is relatively narrow, and the general pattern and magnitude is close to that of Shen et al. (2008). Alcamo et al. (2007) reported a range much larger than any of our scenarios. Alcamo et al. (2007) assumed that the per capita water use in developing countries increases to the current mid-range levels of the USA and Europe. This corresponds to more than $400 \mathrm{Lday}^{-1}$ person $^{-1}$, which is close to our assumption for SSP3. Moreover, because of the formulation used by Alcamo et al. (2007), per capita water withdrawal increases much more rapidly than in our model. These two factors explain the differences between our results and theirs. Shen et al. (2008) assumed more conservative growth, and eventually, their scenarios and ours approach each other.

The assumptions of municipal water modeling are based on historical time series analysis (Figs. 7 and 8), but the limitations should be carefully noted. First, we applied these assumptions uniformly across the globe. This eventually leads to a very homogeneous global water use (i.e. all nations withdraw $200 \mathrm{~L} \mathrm{day}^{-1}$ person $^{-1}$ of municipal water), which might be unrealistic. In reality, municipal water use reflects the customs and climate of each region. Current water use is quite diverse across various nations as shown in Figs. 7 and 8. Second, in some cases, domestic and municipal water is not strictly separated in global reports; hence care must be taken with comparisons. Following the categorization of AQUASTAT, we separated water use into agricultural, industrial, and municipal water, but some earlier studies have also reported domestic water, which primarily indicates the water use of households. We simply judged that a strict separation is impractical because of the limitations of data availability.

\section{Conclusions}

This study developed a global water use scenario that is compatible with the Shared Socio-economic Pathways (SSPs), which are a part of a new set of scenarios for global climate change. The water use scenario was developed to reflect both the quantitative and qualitative descriptions of each SSP. The scenarios include the five factors of irrigated area, crop intensity, irrigation efficiency for estimation of potential irrigation water demand, and withdrawal-based potential industrial and municipal water demand that are required to run modern global hydrological models. All of these scenarios are gridbased at a spatial resolution of $0.5^{\circ} \times 0.5^{\circ}$ and cover the entire 21 st century. The accompanying paper (Hanasaki et al., 2013) analyzes global water availability and scarcity in the 21 st century by utilizing the water use scenarios developed here.

The method proposed in this study is simple but carefully designed to function with currently available information of SSPs. The technical feasibility of growth in industrial and municipal water use was taken into account by using the parameters obtained from historical analyses. Projected water use in five scenarios of this study covers the vast range of existing projections. SSPs were developed based on the latest socio-economic data and modeling techniques. The final products of SSPs are under review, but at least AIM-SSP offered projections in more detailed categorization and finer spatial resolution than SRES. These advantages were utilized in this study. It is a big challenge to project the society, industry, and technology in the future, much more for water use. However, water availability could be a limiting factor of all of them. Further efforts are needed to better project water use in the future consistent with socio-economic conditions.

To the authors' knowledge, this is the first study to present a global water use scenario compatible with SSPs. We proposed a method for interpreting quantitative scenarios of SSPs using the key parameters of water use modeling, which might be applicable to other disciplines. This study can be considered an expansion of the new set of global change scenarios (Moss et al., 2010), adding details on the water sector. Our results will be useful for further comprehensive projections of the future global environment in the 21 st century. 
Acknowledgements. The authors are grateful to Keigo Noda, Taikan Oki, and two anonymous reviewers for their useful comments. This research was supported by the Environment Research and Technology Development Fund (S-10 and A1103) of the Ministry of the Environment, Japan, CREST of the Japan Science and Technology Agency, and the National Institute for Environmental Studies Special Research Fund.

Edited by: J. Liu

\section{References}

Alcamo, J., Döll, P., Henrichs, T., Kaspar, F., Lehner, B., Rösch, T., and Siebert, S.: Development and testing of the WaterGAP 2 global model of water use and availability, Hydrolog. Sci. J., 48, 317-337, 2003a.

Alcamo, J., Döll, P., Henrichs, T., Kaspar, F., Lehner, B., Rösch, T., and Siebert, S.: Global estimates of water withdrawals and availability under current and future "business-as-usual" conditions, Hydrolog. Sci. J., 48, 339-348, 2003b.

Alcamo, J., van Vuuren, D., Cramer, W., Alder, J., Bennett, E., Carpenter, S., Christensen, V., Foley, J., Märker, M., Masui, T., Morita, T., O’Neill, B., G. Peterson, G., Ringler, C., Rosegrant, M., and Schulze, K.: Changes in ecosystem services and their drivers across the scenarios, in: Ecosystems and Human Wellbeing: Scenarios, edited by: Hassan, R., Scholes, R., and Ash, N., Island Press, Washington, DC, 299-373, 2005.

Alcamo, J., Flörke, M., and Märker, M.: Future long-term changes in global water resources driven by socio-economic and climatic changes, Hydrolog. Sci. J., 52, 247-275, 2007.

Arnell, N. W.: Climate change and global water resources: SRES emissions and socio-economic scenarios, Global Environ. Chang., 14, 31-52, 2004.

Bruinsma, J.: World agriculture: towards 2015/2030 An FAO perspective, EarthScan, 2003.

Center for International Earth Science Information Network (CIESIN) Columbia University, and Centro Internacional de Agricultura Tropical (CIAT): Gridded Population of the World Version 3 (GPWv3): Population Grids, Socioeconomic Data and Applications Center (SEDAC) Columbia University, Palisades, NY, 2005.

de Fraiture, C., Wichelns, D., Rockström, J., and Kemp-Benedict, E.: Looking ahead to 2050: scenarios of alternative investment approaches, in: Water for food, water for life: a comprehensive assessment of water management in agriculture, edited by: Molden, D., Earthscan, London, 2007.

Döll, P.: Impact of climate change and variability on irrigation requirements: A global perspective, Clim. Change, 54, 269-293, 2002.

Döll, P. and Siebert, S.: A digital global map of irrigated areas, ICID J., 49, 55-66, 2000.

Döll, P. and Siebert, S.: Global modeling of irrigation water requirements, Water Resour. Res., 38, 1037, doi:10.1029/2001WR000355, 2002.

Food and Agriculture Organization (FAO): AQUASTAT, available at: http://www.fao.org/nr/water/aquastat/main/index.stm (last access: 25 October 2012), 2011.

Faurès, J.-M., Svendsen, M., and Turral, H.: Reinventing irrigation, in: Water for Food, Water for Life, edited by: Molden, D., Earth- scan, London, UK, 353-394, 2007.

Flörke, M. and Eisner, S.: Development of spatially detailed global estimates of 20th and 21 st century sectoral water requirements, WATCH Technical Report Number 46, CESR, University of Kassel, Kassel, Germany, 25, 2011.

Flörke, M., Kynast, E., Bärlund, I., Eisner, S., Wimmer, F., and Alcamo, J.: Domestic and industrial water uses of the past 60 years as a mirror of socio-economic development: A global simulation study, Global Environ. Chang., 23, 144-156, doi:10.1016/j.gloenvcha.2012.10.018, 2013.

Hanasaki, N., Kanae, S., Oki, T., Masuda, K., Motoya, K., Shirakawa, N., Shen, Y., and Tanaka, K.: An integrated model for the assessment of global water resources - Part 1: Model description and input meteorological forcing, Hydrol. Earth Syst. Sci., 12, 1007-1025, doi:10.5194/hess-12-1007-2008, 2008a.

Hanasaki, N., Kanae, S., Oki, T., Masuda, K., Motoya, K., Shirakawa, N., Shen, Y., and Tanaka, K.: An integrated model for the assessment of global water resources - Part 2: Applications and assessments, Hydrol. Earth Syst. Sci., 12, 1027-1037, doi:10.5194/hess-12-1027-2008, 2008b.

Hanasaki, N., Fujimori, S., Yamamoto, T., Yoshikawa, S., Masaki, Y., Hijioka, Y., Kainuma, M., Kanamori, Y., Masui, T., Takahashi, K., and Kanae, S.: A global water scarcity assessment under Shared Socio-economic Pathways - Part 2: Water availability and scarcity, Hydrol. Earth Syst. Sci., 17, 2393-2413, doi:10.5194/hess-17-2393-2013, 2013.

Hayashi, A., Akimoto, K., Tomoda, T., and Kii, M.: Global evaluation of the effects of agriculture and water management adaptations on the water-stressed population, Mitig. Adapt. Strateg. Glob. Change., 18, 591-618, doi:10.1007/s11027-012-9377-3, 2012.

Kainuma, M., Matsuoka, Y., and Morita, T.: Climate policy assessment: Asia-Pacific Integrated Modeling, Springer, Tokyo, Japan and New York, USA, 2002.

Kriegler, E., O’Neill, B. C., Hallegatte, S., Kram, T., Lempert, R. J., Moss, R. H., and Wilbanks, T.: The need for and use of socioeconomic scenarios for climate change analysis: A new approach based on shared socio-economic pathways, Global Environ. Change, 22, 807-822, doi:10.1016/j.gloenvcha.2012.05.005, 2012.

Kundzewicz, Z. W., Mata, L. J., Arnell, N. W., Döll, P., Kabat, P., Jiménez, B., Miller, K. A., Oki, T., Sen, Z., and Shiklomanov, I. A.: Freshwater resources and their management, in: Climate Change 2007: Impacts, Adaptation and Vulnerability, Contribution of Working Group II to the Fourth Assessment Report of the Intergovernmental Panel on Climate Change, edited by: Parry, M. L., Canziani, O. F., Palutikof, J. P., van der Linden, P. J., and Hanson, C. E., Cambridge University Press, Cambridge, UK, 173-210, 2007.

Liu, J., Zehnder, A. J. B., and Yang, H.: Global consumptive water use for crop production: The importance of green water and virtual water, Water Resour. Res., 45, W05428, doi:10.1029/2007WR006051, 2009.

Liu, J. and Yang, H.: Spatially explicit assessment of global consumptive water uses in cropland: Green and blue water, J. Hydrol., 384, 187-197, 2010.

Meehl, G. A., Covey, C., Delworth, T., Latif, M., McAvaney, B., Mitchell, J. F. B., Stouffer, R. J., and Taylor, K. E.: The WCRP CMIP3 Multimodel Dataset: A new era in climate change 
research, B. Am. Meteorol. Soc., 88, 1383-1394, 2007.

Moss, R. H., Edmonds, J. A., Hibbard, K. A., Manning, M. R., Rose, S. K., van Vuuren, D. P., Carter, T. R., Emori, S., Kainuma, M., Kram, T., Meehl, G. A., Mitchell, J. F. B., Nakicenovic, N., Riahi, K., Smith, S. J., Stouffer, R. J., Thomson, A. M., Weyant, J. P., and Wilbanks, T. J.: The next generation of scenarios for climate change research and assessment, Nature, 463, 747-756, doi:10.1038/nature08823, 2010.

Nakicenovic, N. and Swart, R.: Special Report on Emissions Scenarios: A Special Report of Working Group III of the Intergovernmental Panel on Climate Change, Cambridge University Press, Cambridge, 612 pp., 2000.

Oki, T. and Kanae, S.: Global hydrological cycles and world water resources, Science, 313, 1068-1072, 2006.

Oki, T., Agata, Y., Kanae, S., Saruhashi, T., and Musiake, K.: Global water resources assessment under climatic change in 2050 using TRIP, IAHS Publication, 280, 124-133, 2003.

O’Neill, B. C., Carter, T. R., Ebi, K. L., Edmonds, J., Hallegatte, S., Kemp-Benedict, E., Kriegler, E., Mearns, L., Moss, R., Riahi, K., van Ruijven, B., and van Vuuren, D.: Meeting Report of the Workshop on the Nature and Use of New Socioeconomic Pathways for Climate Change Research, National Center for Atmospheric Research, Boulder, CO, 2012.

Otaki, Y., Otaki, M., and Yamada, T.: Attempt to establish an industrial water consumption distribution model, J. Water Environ. Technol., 6, 85-91, 2008.

PUB Singapore's National Water Agency: Water Conservation Awareness Programme, available at: http://www.pub.gov. sg/conserve/households/wacprogramme/pages/default.aspx (last access: 30 September 2012), 2012.

Rosegrant, M. W., Cai, X., and Cline, S. A.: World Water and Food to 2025: Dealing with Scarcity, International Food Policy Research Institute, Washington, D.C., 2002.

Rosegrant, M., Fernandez, M., and Shinha, A.: Looking into the future for agriculture and AKST, in: Agriculture at a Crossroads, edited by: McIntyre, B. D., Herren, H. R., Wakhungu, J., and Watson, R. T., Island Press, Washington, D.C., 2009.

Rost, S., Gerten, D., Bondeau, A., Lucht, W., Rohwer, J., and Schaphoff, S.: Agricultural green and blue water consumption and its influence on the global water system, Water Resour. Res., 44, W09405, doi:10.1029/2007WR006331, 2008.

Seckler, D., Amarasinghe, U., Molden, D., de Silva, R., and Barker, R.: World water demand and supply. 1990 to 2025: Scenarios and issues, International Water Management Institute, Colombo, Sri Lanka, 1998.

Shen, Y., Oki, T., Utsumi, N., Kanae, S., and Hanasaki, N.: Projection of future world water resources under SRES scenarios: Water withdrawal, Hydrolog. Sci. J., 11-33, doi:10.1623/hysj.53.1.11, 2008.
Shiklomanov, I. A.: Appraisal and assessment of world water resources, Water Int., 25, 11-32, 2000.

Shiklomanov, I. A. and Rodda, J. C.: World Water Resources at the Beginning of the Twenty-First Century, Cambridge University Press, 2003.

Siebert, S., Döll, P., Hoogeveen, J., Faures, J.-M., Frenken, K., and Feick, S.: Development and validation of the global map of irrigation areas, Hydrol. Earth Syst. Sci., 9, 535-547, doi:10.5194/hess-9-535-2005, 2005.

Siebert, S., Hoogeveen, J., and Frenken, K.: Irrigation in Africa, Europe and Latin America. Update of the Digital Global Map of Irrigated areas to Version 4, University of Frankfurt (Main), Germany and FAO, Rome, Italy, 134, 2006.

Smith, M.: CROPWAT - A computer program for irrigation planning and management, FAO, Rome, 1992.

Taylor, K. E., Stouffer, R. J., and Meehl, G. A.: An overview of cmip5 and the experiment design, B. Am. Meteorol. Soc., 93, 485-498, doi:10.1175/BAMS-D-11-00094.1, 2012.

United Nations: World Population Prospects: The 2010 Revision, Volume I: Comprehensive Tables ST/ESA/SER.A/313, 481, 2011.

Vassolo, S. and Döll, P.: Global-scale gridded estimates of thermoelectric power and manufacturing water use, Water Resour. Res., 41, W04010, doi:10.1029/2004WR003360, 2005.

Vörösmarty, C. J., Green, P., Salisbury, J., and Lammers, R. B.: Global water resources: Vulnerability from climate change and population growth, Science, 289, 284-288, 2000.

Voß, F. and Flörke, M.: Spatially explicit estimates of past and present manufacturing and energy water use, WATCH Technical Report Number 23, CESR, University of Kassel, Kassel, Germany, 17, 2010.

Voß, F., Flörke, M., and Alcamo, J.: Preliminary spatially explicit estimates of past and present domestic water use, WATCH Technical Report Number 17, CESR, University of Kassel, Kassel, Germany, 16, 2009.

van Vuuren, D., Edmonds, J., Kainuma, M., Riahi, K., Thomson, A., Hibbard, K., Hurtt, G., Kram, T., Krey, V., Lamarque, J.F., Masui, T., Meinshausen, M., Nakicenovic, N., Smith, S., and Rose, S.: The representative concentration pathways: an overview, Clim. Change, 109, 5-31, doi:10.1007/s10584-0110148-Z, 2011.

Wada, Y., van Beek, L. P. H., Viviroli, D., Dürr, H. H., Weingartner, R., and Bierkens, M. F. P.: Global monthly water stress: 2. Water demand and severity of water stress, Water Resour. Res., 47, W07518, 10.1029/2010wr009792, 2011.

Wisser, D., Fekete, B. M., Vörösmarty, C. J., and Schumann, A. H.: Reconstructing 20th century global hydrography: a contribution to the Global Terrestrial Network- Hydrology (GTN-H), Hydrol. Earth Syst. Sci., 14, 1-24, doi:10.5194/hess-14-1-2010, 2010.

World Bank: World Development Indicators 2009, World Bank, Washington, D.C. USA, 2009. 